\title{
Bulk Liquid Membranes for Separation and Recovery of Pharmaceutical Products
}

\author{
ECATERINA ANCA SERBAN ${ }^{1,2}$, IOANA DIACONU2*, ELENA RUSE², GHEORGHE BATRINESCU1, GHEORGHE NECHIFOR ${ }^{2}$, \\ MIHAI NITA LAZAR ${ }^{1}$ \\ ${ }^{1}$ National Research and Development Institute for Industrial Ecology ECOIND, $71-73$ Drumul Podul Dambovitei Str., 060652, \\ Bucharest, Romania \\ ¿University Politehnica of Bucharest, Faculty of Applied Chemistry and Materials Science, 1-7 Polizu Street, 011061, \\ Bucharest, Romania
}

\begin{abstract}
In this present paper the behavior of two important pharmaceutical compounds, namely: nicotinic acid (vitamin $P P / B_{3}$ ) and para-aminobenzoic acid (vitamin $B_{1}$ ) to the transport through a liquid membrane of chloroform containing Aliquat 336 have been studied. The influence of operational parameters such as: solute concentration in the feed phase, stripping agent concentration in the stripping phase, transport time was monitored. The assessment of the obtained results allowed establishing of optimal transport conditions as well as identification of a kinetic transportmodel for nicotinic acid corresponding to consecutive irreversible 1st order reactions. The maximum transport efficiency was $96 \%$ and it was obtained at a concentration of $10^{4} \mathrm{~mol} / \mathrm{L}$ nicotinic acid in the feed phase and a concentration of $1 \mathrm{~mol} / \mathrm{L}$ sodium hydroxide in the stripping phase. The transporttime necessary to achieve this efficiency was $6 \mathrm{~h}$. The results obtained led to important conclusions regarding the possibility of separating these two compounds. Analytical control of the process was done spectrophotometrically. The maximum absorbance was obtained at their characteristic wavelengths, namely $262 \mathrm{~nm}$ for nicotinic acid and respectively $267 \mathrm{~nm}$ for para-aminobenzoic acid.
\end{abstract}

Keywords: nicotinic acid, para-aminobenzoic acid, bulk liquid membrane transport, separation of pharmaceutical products

The discharge of a high amount of pharmaceutical compounds into industrial effluents, following anthropogenic activities, represents a risk for the human being, due to high toxicity, non-biodegradable and bio accumulative characteristics even at a very low concentration [1].

For efficient removal of these pharmaceutical compounds from aqueous solutions, numerous chemical and physical technologies are used, such as: membrane separation, ion exchange, chemical precipitation, adsorption and catalytic oxidation through multiple recoveries. Among the separation processes we can mention: separation through bulk liquid membranes technique, liquids extraction, membrane extraction, ultrafiltration, electro dialysis, direct distillation, anion exchange, adsorption, precipitation in the chemical industry, all have been used to recover organic acids from aqueous solutions. Extraction is often the most appropriate, being considered an efficient primary separation step for bio-products recovery [2].

Among the techniques for the wastewater treatment, liquid membranes are expected to be the most suitable due to the results obtained after an applicability of over 40 years in the fundamental studies, where the transport and separation of the following compounds were pursued: metal ions and phenolic compounds and phenols, amines, aminoacids and numerous pharmaceutical products, for example: indole-3-acetic acid, nicotinic acid, paraaminobenzoic acid, salicylic acid, acetaminophen etc. [39].

Pertraction involves extraction and transport through liquid membranes, being a separation technique that is achieved by transferring the solute between the aqueous phases at $\mathrm{pH}$ with different values separated by a liquid membrane. Efficiency and selectivity can be improved by adding a carrier to the liquid membrane, such as organophosphorus compounds, long chain amines or crown ethers, etc. The separation process is called the facilitated transport [5, 10-11].

Organic acids, such as nicotinic acid and paraaminobenzoic acid, are widely used in the pharmaceutical, biochemical and food industries to be considered important chemical products.

Nicotinic acid is also known as vitamin B3, vitamin PP, 3-pyridine carboxylic acid or 3-picolinic acid. Nicotinic acid and nicotinic acid amide are the two forms of vitamin $B_{3}$ the latter representing the active form of vitamin $[2,11$ 15].

Nicotinic acid is a derivative of the pyridine ring. This vitamin in the body is in protein-conjugated form, it enters the structure of niacin enzymes, obtaining two coenzymes, namely $\mathrm{NAD}^{+}$(nicotinamide adenine dinucleotide) and $\mathrm{NADP}^{+}$(nicotinamidadenine dinucleotide phosphate), being coenzymes of dehydrogenases involved in multiple oxidoreduction reactions, with an important role in cellular respiration. $\mathrm{NAD}^{+}$and $\mathrm{NADP}^{+}$adds electrons and protons from substrates that oxidize. Thus occurs, reducing the pyridine ring through adding electrons and protons to NAD ${ }^{+}$ and NADP ${ }^{+}[2,13,16-17]$.

Para-aminobenzoic acid (PABA), also known as vitamin $B_{10}$ or R-factor, has been demonstrated to be part of folic acids. Para-aminobenzoic acid is part of pteroylglutamate, is considered a provitamin for some bacteria and growth factor for some animals, and in the human body has the ability to synthesize folate [18-20].

Nicotinic acid presents antipellagra activity [2] and para-aminobenzoic acid is used as an additive in cosmetic sunscreen products, in medical applications on skin protection against vitiligo, scleroderma and in the treatment of male infertility [20-22].

\footnotetext{
*email: diaconuioana12@yahoo.com
} 
Para-aminobenzoic acid is also used in diagnostic tests for the gastrointestinal tract. It has been found to be an inducer of endogenous interferon and immunomodulator and it has a synergistic virucidal antiviral effect combined with chemical drugs having the properties of a direct anticoagulant [18, 23].

Nicotinic acid consumed in high dose, blocks the breakdown of fat in the adipose tissue, modifying lipid levels in the blood, and is useful in the treatment of hyperlipidemia.

In the practice of performance sports, vitamin PP is forbidden, because in large quantities the drug screening tests give errors, especially for drugs, and a slight deficiency slows down metabolism [22, 24].

Nicotinic acid is mainly obtained by chemical synthesis using 3-picoline or 2-methyl-5-ethylpyridine as feedstock. The production of nicotinic acid and nicotinamide can be enhanced by the enzymatic conversion of 3-cyanopyridine or biosynthesis [13].

Para-aminobenzoic acid is produced by chemical synthesis using methyl 4-formylbenzoate as feedstock [28] or biosynthesis through mutant strains by E. coli $[18,25]$.

Nicotinic acid has six metabolites, respectively nicotinuric acid, nicotinamide, 1-methy-4-pyridone-5carboxamide, 1-methy-2-pyridone-5-carboxamide, nicotinamide-N-oxide and 1-methyl-nicotinamide [26].

Para-aminobenzoic acid is insoluble with waterimmiscible organic solvents, and separation by physical extraction is not achieved, however, extraction is possible by adding a carrier in the solvent, which may react with this acid, resulting in the formation of a hydrophobic acid. The chemical structure of para-aminobenzoic acid, consisting of an acidic group, - $\mathrm{COOH}$ and a basic group $\mathrm{NH}_{2}$, can influence the efficiency of the reactive extraction.

Efficiency can be improved by adding amine and organophosphorus type extractors. There are other factors thathel $p$ improve the efficiency of reactive extraction such as: aqueous phase $\mathrm{pH}$, solvent polarity and the type and concentration of the extractant [5, 18, 27-30].

Liquid-liquid extraction is limited to ionisable compounds and carboxyl compounds, due to their low solubility in ordinary organic solvents. But using extractor in the organic phase extraction takes place.

Nicotinic acid extraction is made possible by the addition of an extractant in the solvent used, which may react with the acid, resulting in a hydrophobic compound, the chemical structure of nicotinic acid contains an acidic group, $-\mathrm{COOH}$ and a basic group, $\mathrm{N}$ from the pyridine core, extraction is made possible by the use of the amine or organophosphoric acid type extracts [29, 31, 32].

In the present paper the transport through bulk liquid membranes of nicotinic acid and para-aminobenzoic acid in the presence of Aliquate 336 is studied.

\section{Experimental part}

Materials and methods

All reagents used in the transport studies were of analytical grade and were used withoutfurther purification. Nicotinic acid, para-aminobenzoic acid and the carrier Aliquat 336, sodium hydroxide used as the stripping agent and the chloroform used as the membrane phase were purchase from Sigma Aldrich. The transport experiments were carried out in a wall in wall transport cell.

The membrane system consisted of: the feed phase aqueous solution of nicotinic acid or para-aminobenzoic acid in the concentration range of $10^{-4}-10^{-3} \mathrm{~mol} / \mathrm{L}$, membrane-Aliquat 336 solution, $10^{-2} \mathrm{~mol} / \mathrm{L}$ in chloroform, the stripping phase - solution of sodium hydroxide in the concentration range $10^{-2}-1 \mathrm{~mol} / \mathrm{L}$. For the preparation of the aqueous phases, distilled water saturated with chloroform was used and the preparation of the membrane phase used chloroform saturated with water. Analytical control of the process was performed spectrophotometrically. The maximum absorbance was obtained at their characteristic wavelengths, namely $262 \mathrm{~nm}$ for nicotinic acid and respectively $267 \mathrm{~nm}$ for $\mathrm{p}$-aminobenzoic acid.

\section{Results and discussions}

In the present paper the behavior at the transport through bulk liquid membranes of two compounds by pharmaceutical importance: nicotinic acid and paraaminobenzoic acid was studied. Since the best results in terms of process efficiency are obtained with nicotinic acid, the experimental study emphasizes the behaviour of this compound in the membrane transport process.

Nicotinic acid is an organic compound with mixed functions. The presence of the carboxyl group results in acidic properties, but at the same time the presence of increased electronic density nitrogen can act as a proton acceptor. As a result, in the aqueous solution, the following equilibriums are possible (scheme 1 ).

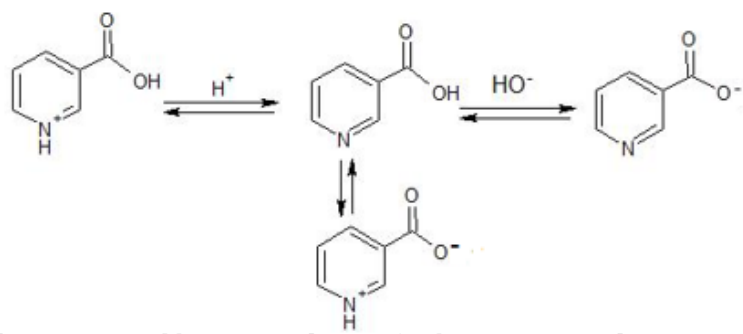

Scheme 1. Equilibriums with transfer by protons in the nicotinic acid solution

The existence of anionic forms and of centers with increased electronic density makes possible the complexation of nicotinic acid with a carrier such as Aliquat 336. Our preliminary experimental results lead us to the hypothesis that the carrier forms a complex with the organic substrate through the centers of increased electron density on the nitrogen atom. For this reason it was used as a feed phase one aqueous solution by the nicotinic acid without $\mathrm{pH}$ correction.

By complexation of nicotinic acid with Aliquat 336 we obtain a hydrophobic entity soluble in the organic membrane. At the interface the membrane phase| stripping phase a decomplexation can take place and thus the nicotinic acid is released.

The influence of some transport parameters such as: the concentration of the nicotinic acid from the feed phase, the concentration of the hydrochloric acid used that as the stripping agent by the stripping phase and the transport time were studied.

The assessment of the transport process was performed by calculating the average flux (J) using the relationship:

where:

$$
J=\frac{V_{F R} \times C_{F R}}{A \times t}
$$

$J=$ average flux

$\mathrm{V}_{\mathrm{FR}}=$ stripping phase volum, $\mathrm{L}$

$C_{F R}^{F R}=$ concentration of the stripping phase, $\mathrm{mol} / \mathrm{L}$

$A \stackrel{F R}{=}$ area of interface membrane/stripping phase, $\mathrm{cm}^{2}$ $\mathrm{t}=$ time of transport, $\mathrm{h}$

\section{Influence of the feed phase concentration}

The influence of the concentration of nicotinic acid from the feed phase in the concentration range $10^{-4}-10^{-3} \mathrm{~mol} / \mathrm{L}$ 
was studied. The efficiency of the pertraction process at the different nicotinic acid concentrations is shown in figure 1.

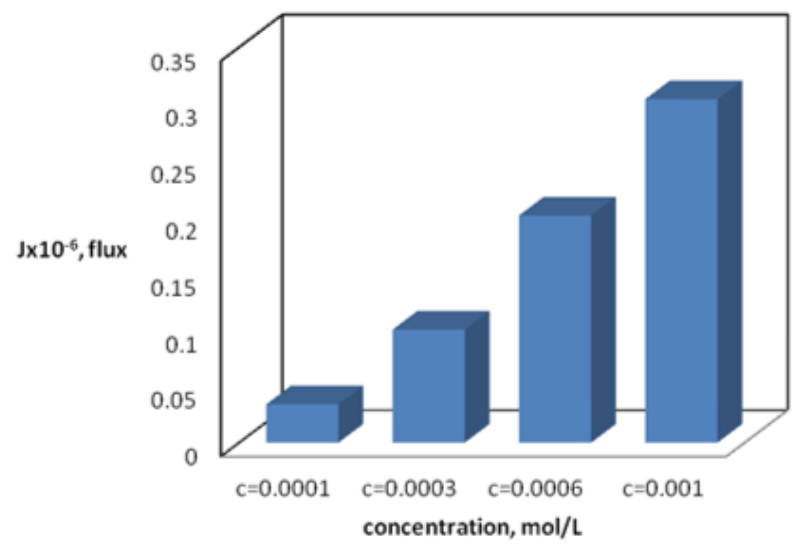

Fig. 1. The influence of the concentration of nicotinic acid in feed phase. The membrane system consisted of: Feed phase - aqueous solution of nicotinic acid in the concentration range of $10^{-4}-10^{-3}$ mol / L.Membrane phase - Aliquat 336 solution, of concentration $10^{-2} \mathrm{~mol} / \mathrm{L}$ in chloroform. Stripping phase - sodium hydroxide solution of concentration $1 \mathrm{~mol} / \mathrm{L}$.

It is found that transport fluxes are higher at the low concentrations of nicotinic acid. These results can be correlated with a higher chemical potential gradient in lower organic substrate concentrations.

\section{Influence of the stripping phase concentration}

As the stripping agent sodium hydroxide $(\mathrm{NaOH})$ was used in the concentration range

$10^{-1}-1 \mathrm{~mol} / \mathrm{L}$. The results obtained through the flux of transport are shown in figure 2 .

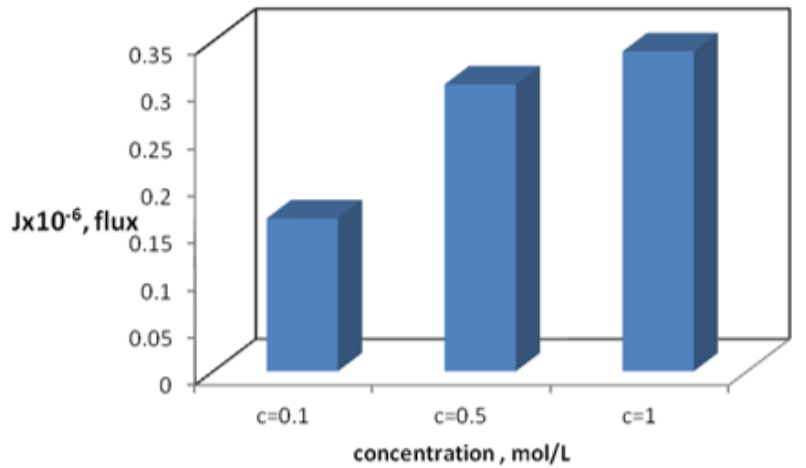

Fig. 2. The influence of the concentration of the sodium hydroxide in stripping phase. The membrane system consisted of: Feed phase - aqueous solution of nicotinic acid by the concentration of

$10^{-4} \mathrm{~mol} / \mathrm{L}$. Membrane phase - Aliquat 336 solution, the

concentration of $10^{-2} \mathrm{~mol} / \mathrm{L}$ in chloroform. Stripping phase sodium hydroxide solution of the concentration range $10^{-1}-1 \mathrm{~mol} / \mathrm{L}$

The stripping agent causes the release of the substrate transported at the interface membrane | stripping phase; thus a higher concentration of stripping agent can influence favorably the transfer of nicotinic acid into the stripping phase.

\section{Influence of the transport time}

In order to optimize the transport through bulk liquid membrane of time an important parameter was studied, namely time. Studies have been conducted for all experimented systems and it has been found that the optimal transport time is $6 \mathrm{~h}$.

The variation in time of reduced concentrations of nicotinic acid led to the conclusion of a kinetic transport model corresponding to consecutive irreversible consecutive reactions according to the scheme:

$$
(A c N)_{F P} \stackrel{k_{1}}{\rightarrow}(A c N)_{M} \stackrel{k_{2}}{\rightarrow}(A c N)_{S P}
$$

where $k_{1}$ si $k_{2}$ represent pseudo-first-order apparent membrane entrance and exit rate constants $\left[\mathrm{s}^{\prime \prime}\right]$.

This kinetic model described by differential equations:

$$
\begin{aligned}
& \frac{d R_{F P}}{d t}=-k_{1} R_{F P}=J_{F P} \\
& \frac{d R_{M}}{d t}=-k_{1} R_{F P}-k_{2} R_{M} \\
& \frac{d R_{S P}}{d t}=-k_{1} R_{M}=J_{S P}
\end{aligned}
$$

$J_{F P} \mathrm{Si} J_{S p}$ is the flux at the entrance and exit of membrane and $R_{F S} R_{M}$ si $R_{F R}$ represent reduced concentrations. The reduced concentration at a specific time $t$ can be calculated in the three phases of membrane system using equations:

$$
\begin{aligned}
& R_{F P}=\frac{C_{F P}}{C_{0}} \\
& R_{M}=\frac{C_{M}}{C_{0}} \\
& R_{S P}=\frac{C_{S P}}{C_{0}}
\end{aligned}
$$

$C_{F P}, C_{M}, C_{S P}$ represent concentrations of the nicotinic acid in feed phase, the membrane and the stripping phase at the time $t$, in $\mathrm{mol} / \mathrm{L}$ $\mathrm{mol} / \mathrm{L}$

$C$ represent initial concentration in the feed phase in

By integrating these equations are obtained relationships:

$$
\begin{gathered}
R_{F P}=e^{-k_{1} t} \\
R_{M}=\frac{k_{1}}{k_{2}-k_{1}}\left(e^{-k_{1} \cdot t}-e^{-k_{2} \cdot t}\right) \\
R_{S P}=1+\frac{1}{k_{1}-k_{2}}\left(k_{2} e^{-k_{1} \cdot t}-k_{1} e^{-k_{2} \cdot t}\right)
\end{gathered}
$$

The kinetic model considered can be correlated with the experimental data with a correlation coefficient of 0.98 only for a concentration of $1 \mathrm{~mol} / \mathrm{L}$ stripping agent.

These observations related to the kinetic behavior of the studied transport systems are exemplified graphically in figure 3.

$$
R_{S P}=1+\frac{1}{k_{1}-k_{2}}\left(k_{2} e^{-k_{1} \cdot t}-k_{1} e^{-k_{2}-t}\right)
$$

In similar transport systems, the behavior of paraaminobenzoic acid (PABA) was also studied. And for this compound the best results are obtained at lower concentrations of organic substrate $\left(10^{-4} \mathrm{~mol} / \mathrm{L}\right)$ and at $\mathrm{NaOH}$ concentrations (stripping agent) of $1 \mathrm{~mol} / \mathrm{L}$. The large differences between transport fluxes of these two compounds (fig. 4) lead to the possibility of their separation. 

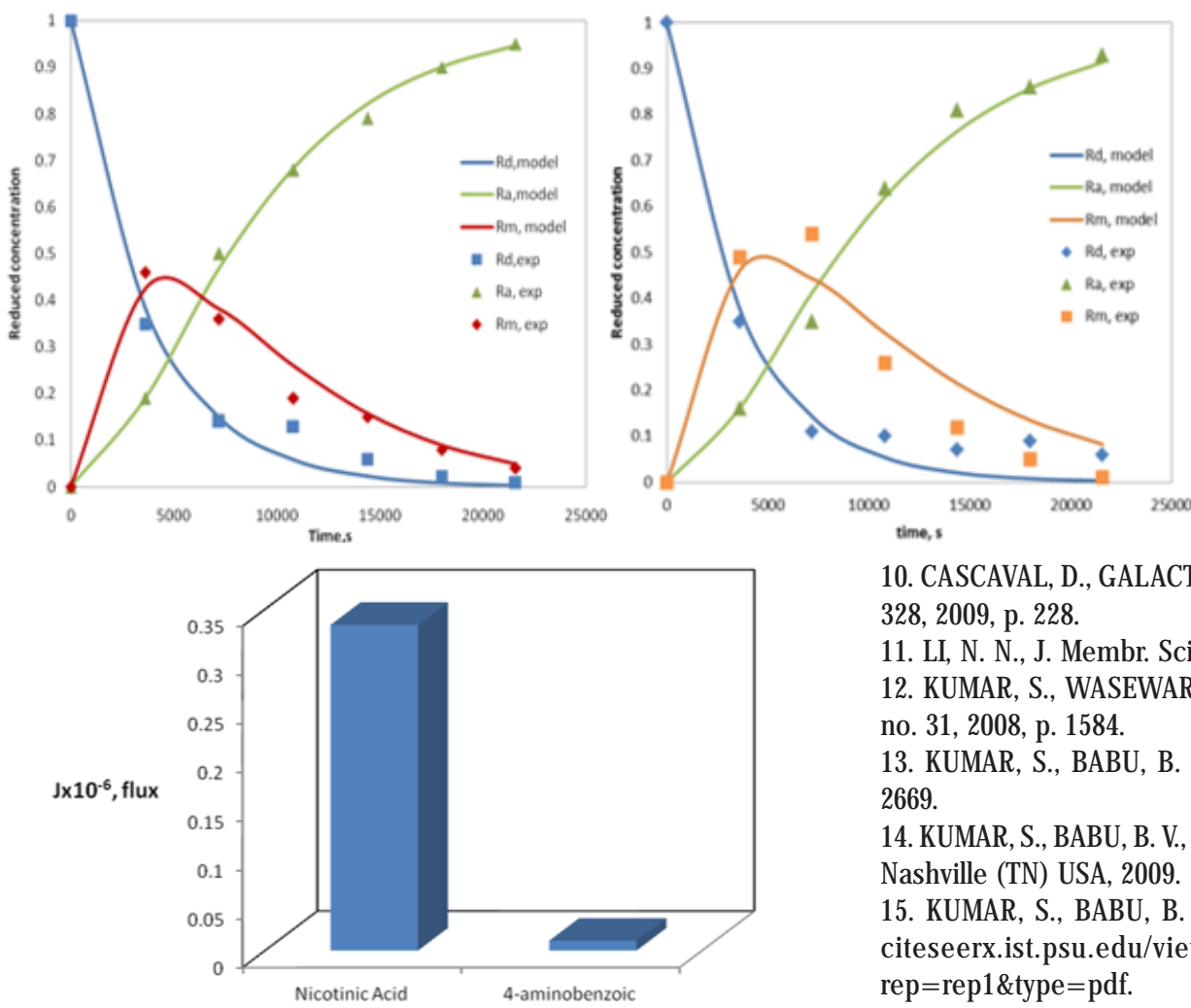

Fig. 4. The transport fluxes of nicotinic acid and p-aminobenzoic acid Experimental conditions: Feed phase - nicotinic acid solution or p-aminobenzoic acid $10^{-4} \mathrm{~mol} / \mathrm{L}$. Membrane phase - Aliquat 336 solution, the concentration of $10^{-2} \mathrm{~mol} / \mathrm{L}$ in chloroform. Stripping phase $-1 \mathrm{~mol} / \mathrm{Lsodium}$ hydroxide solution.

\section{Conclusions}

In the present paper, it was studied the transport of nicotinic acid through bulk liquid membrane using Aliquat 336 as a carrier. The experimental results obtained have shown that the process can result in very good efficiency at low concentrations of nicotinic acid in the feed phase.

Thus, for a membrane system formed from the feed phase of nicotinic acid solution at concentration $10^{-4} \mathrm{~mol} /$ $L$, membrane phase from Aliquat 336 solution at concentration $10^{-2} \mathrm{~mol} / \mathrm{L}$ in chloroform, and stripping phase from $1 \mathrm{~mol} / \mathrm{L}$ sodium hydroxide solution, by the nicotinic acid pertraction takes place in a yield of over $90 \%$.

For the membrane systems where the stripping phase is a sodium hydroxide concentration of $1 \mathrm{~mol} / \mathrm{L}$ by transport, the process devolve after a one-order kinetics corresponding to irreversible consecutive reactions.

\section{References}

1. WANG, X., ZENG, Q., HUANG, J., LIU, Y.-N., Desalin. Water Treat., no. 54, 2015, p.1893.

2. SENOL, A., Turk J. Chem., no. 26, 2002, p. 77.

3. SZCZEPANSKI, P., TANCZOS, S.K., GHINDEANU, L.D., WODZKI, R., Sep. Purif. Technol., no. 132, 2014, p. 616.

4. KUMAR, S., BABU, B. V., J. Fut. Eng. Technol., no. 3, 2008, p. 19.

5. KLOETZER L., GALACTION A.-I., CASCAVAL D., Rev. Med. Chir. Soc. Med. Nat., 114, no. 1, 2010, lasi.

6. DIACONU, I., MIREA, C.M., SERBAN, E. A., RUSE, E., NECHIFOR, GH., Rev. Chim. (Bucharest), 66, no. 7, 2015, p. 926.

7. SERBAN, E.A., DIACONU, I., RUSE, E., EFTIMIE TOTU, E., NECHIFOR, GH., Rev. Roum. Chim., 62, no. 6-7, 2017, p. 505.

8. MIREA, C.M., DIACONU, I., SERBAN, E. A., RUSE, E., NECHIFOR, GH., Rev. Chim. (Bucharest), 67, no. 5, 2016, p. 926.

9. a ERBAN, E.A., DIACONU, I., MIREA, C.M., RUSE, E., Rev. Chim. (Bucharest), 67, no. 4, 2016, p. 634. 328, 2009, p. 228. no. 31, 2008, p. 1584. 2669. Nashville (TN) USA, 2009. rep $=$ repl\&type $=$ pdf. Technol., no. 42, 3, p. 222. Eng. Q., 2, no. 24, 2010, p. 149. Lett, 15, no. 2, 2010, p. 5146. no. 45,2010 , p. 1440 . 2010, p.1195. Eng. Q., no. 24, 2, 2010, p. 149. and the Industry, 2017, p. 296. p. 367. 2017, p. 248. no. 45, 2010, p. 1440. 14, 2008, p. 159. App., 5, no. 6, 2014, p. 506. 2014, p. 377

Manuscript received: 17.08 .2018
Fig. 3. Variation of reduced concentrations of nicotinic acid in time. Experimental conditions: Feed phase nicotinic acid solution $3 \times 10^{-4} \mathrm{~mol} / \mathrm{L}$ (a) and $6 \times 10^{-4} \mathrm{~mol} / \mathrm{L}$ (b). Membrane phase Aliquat 336 solution, the concentration of $10^{-2} \mathrm{~mol} / \mathrm{L}$ in chloroform. Stripping phase $-1 \mathrm{~mol} / \mathrm{L}$ sodium hydroxide solution.

10. CASCAVAL, D., GALACTION, A. -I., TURNEA, M., J. Membr. Sci., no.

11. LI, N. N., J. Membr. Sci., no. 3, 1978, p. 265.

12. KUMAR, S., WASEWAR, K. L., BABU, B. V., Chem. Eng. Technol.,

13. KUMAR, S., BABU, B. V., J. Chem.Eng. Data., no. 54, 9, 2009, p.

14. KUMAR, S., BABU, B. V., Proceedings of 2009-AIChE Annual Meeting,

15. KUMAR, S., BABU, B. V., Conference Proceedings, 2010, http:// citeseerx.ist.psu.edu/viewdoc/download?doi= 10.1.1.294.6493\&

16. CANTARELLA, M., CANTARELLA, L., GALLIFUICO, A., INTELLINI, R., KAPLAN, O., SPERA, A., MARTINKOVA, L., Enzyme Microb.

17. KUMAR, S., 2010, Intensification of recovery of carboxylic acids using reactive extraction, Ph.D. thesis, BIRLA Institute of technology and science (BITS) Pilani (Rajasthand), India

18. GALACTION, A.-I., KLOETZER, L., CASCAVAL, D., Chem. Biochem.

19. KLOETZER L., GALACTION A.-I., CASCAVAL D., Rom. Biotech.

20. KLOETZER L., GALACTION A.-I., CASCAVAL D., Sep. Sci. Technol.,

21. CASCAVAL D., GALACTION A.-I., Environ. Eng. Manage. J., 9, no. 9,

22. GALACTION A.-I., KLOETZER L., CASCAVAL D., Chem. Biochem.

23. MARTHE, L., STOICA, C., CHIRIAC, L. F., GALAON, T., NITA-LAZAR, $M .$, Proceedings book, $20^{\text {th }}$ International Symposium The Environment

24. KUMAR, S., BABU, B. V., Chem. Biochem. Eng. Q., 3, no. 23, 2009,

25. BANCIU, A. R., NITA-LAZAR, M., NICULESCU, L. D, Proceedings book, $20^{\text {th }}$ International Symposium The Environment and the Industry,

26. LI, A.C., CHEN, Y.-L., JUNGA, H., SHOU, W. Z., JIANG, X., NAIDONG, W., Chromatographia, 2003, 58, no. 11/12, p. 723.

27. KLOETZER, L., GALACTION, A. -I., CASCAVAL, D., Sep. Sci. Technol.,

28. CASCAVAL, D., GALACTION, A.-I., BLAGA, A.C., CAMARUT, M., Sep. Sci. Technol., no. 42, 2007, p. 1.

29. GALACTION A.-I., CAMARUT, M., CASCAVAL, D., CI \& CEQ, 3, no.

30. KUMAR, S., KAMSONLIAN, S., CHOMAL, N., Int. J. Chem. Eng.

31. GANORKAR, P.V., JADHAV, S.M., GAIKWAD, S.G., IJ ATES, 02, no. 11,

32. CASCAVAL, D., BLAGA, A. C., CAMARUT, M., GALACTION, A.-I., Sep. Sci. Technol., no. 42, 2007, p. 389. 